\title{
Montelukast as add-on therapy to inhaled corticosteroids in the treatment of mild to moderate asthma: a systematic review
}

\author{
S Joos, ${ }^{1}$ A Miksch, ${ }^{1}$ J Szecsenyi, ${ }^{1}$ B Wieseler, ${ }^{2}$ U Grouven, ${ }^{2}$ T Kaiser, $^{2}$ A Schneider ${ }^{1}$
}

${ }^{1}$ Department of General Practice and Health Services Research, University Hospital of Heidelberg, Heidelberg, Germany; ${ }^{2}$ Institute for Quality and Efficiency in Health Care (Institut für Qualität und Wirtschaftlichkeit im Gesundheitswesen, IOWIG), Cologne, Germany

Correspondence to: Dr S Joos, Department of General Practice and Health Services Research, University Hospital of Heidelberg, Voßstr 2, D-69115 Heidelberg, Germany; stefanie.joos@ med.uni-heidelberg.de

Received 20 March 2007 Revised 18 April 2007 Accepted 18 April 2007

\section{ABSTRACT}

Objective: To systematically review the evidence for the medium to long term benefits and risks of montelukast as add-on therapy to inhaled corticosteroids (ICS) in comparison with placebo and active controls in mild to moderate asthma.

Data sources: Medline, Embase, Cochrane Register of Controlled Trials, reference lists of retrieved articles, clinical trial registries and study results databases.

Review methods: Systematic review of randomised controlled trials (duration $\geqslant 12$ weeks) in adolescents and adults comparing montelukast/ICS versus ICS monotherapy or montelukast/ICS versus active control/ICS. Metaanalyses were conducted where feasible. The main focus was on clinical outcomes (eg, exacerbations). Adverse events were also assessed.

Results: 13 studies meeting all of the inclusion criteria were identified: 7 studies, including constant or tapered doses of ICS, compared montelukast/ICS with ICS monotherapy. Six studies compared add-on montelukast with an add-on active control (salmeterol). Overall, the data indicated that montelukast/ICS was clinically more effective than ICS monotherapy. The ICS sparing potential of montelukast was clearly demonstrated in one study. Montelukast/ICS and ICS monotherapy showed similar safety profiles. In the active controlled studies, montelukast/ICS was clinically less effective than salmeterol/ICS in the 12 week trials (pooled proportion of patients with $\geqslant 1$ exacerbation: $p=0.006$ ). However, separate analysis of active controlled 48 week trials showed comparable proportions for patients with $\geqslant 1$ exacerbation in both groups.

Conclusions: Montelukast as add-on therapy to ICS improves control of mild to moderate asthma compared with ICS monotherapy. Although the addition of salmeterol to ICS is clinically as effective as or even more effective than the addition of montelukast, montelukast may have a better long term safety profile and offer a treatment alternative for asthma patients.

Asthma is characterised by a chronic inflammation process with increased numbers of activated eosinophils, mast cells, macrophages and T lymphocytes in the airway mucosa and lumen, which produce mediators of inflammation such as histamine, prostaglandins and leucotrienes. Cysteinyl leucotrienes are potent inflammatory mediators produced by the 5-lipoxygenase pathway of arachidonic acid metabolism, and are believed to play a major role in the pathophysiology of asthma by mediating bronchoconstriction and inflammatory reactions. ${ }^{1}$

Leucotriene modifiers, including leucotriene receptor antagonists (LTRA), are a relatively new class of antiasthmatic drugs. Evidence exists that LTRA, by blocking the leucotriene receptors of the smooth airway muscles, reduce airway eosinophilic inflammation and alleviate symptoms of airway obstruction. $^{23}$ Many clinical trials have shown LTRA to be effective in asthma therapy. ${ }^{4}$ They also have the advantage of being administered orally. However, as inhaled corticosteroids (ICS) are more effective than LTRA in reducing asthma exacerbations, ${ }^{5}$ ICS remain the first choice in asthma management whereas LTRA are recommended as an add-on therapy to ICS. ${ }^{6-8}$

In a Cochrane review by Ducharme, the efficacy of LTRA as add-on therapy to ICS was assessed, and LTRA were shown to achieve modest improvement in asthma control. ${ }^{9}$ In a further Cochrane review by Ram et al, LTRA were found to be inferior to long acting $\beta_{2}$ agonists (LABA) in asthmatic patients whose symptoms were suboptimally controlled with ICS therapy. ${ }^{10}$ Trials with a relatively short duration of treatment (minimum of 28 days) were included in both Cochrane reviews. However, conclusions about the long term efficacy (including the possible development of tolerance) and safety of antiasthmatic drugs in chronic asthma should be supported by trials of at least 6 months' duration. ${ }^{611}$ Long term drug effects may be a crucial point when comparing LTRA with LABA as add-on therapies. Pooling of data without a separate analysis of long term trials may make it difficult to identify these long term effects.

In most European countries, montelukast is the only approved LTRA, and is licensed as an add-on therapy to ICS in patients with mild to moderate chronic asthma. Both Cochrane reviews (as well as most other previous reviews) included LTRA not approved in Europe (eg, zafirlukast and pranlukast). ${ }^{5} 9101213$ Therefore, the results of these reviews are not applicable to the European healthcare setting and to clinical practice guidelines, such as the British and German asthma guidelines. ${ }^{78}$ Furthermore, many previous reviews focused on lung function as a primary outcome, and less emphasis was placed on clinical outcomes. $^{5} 9101213$

This systematic review evaluates the scientific evidence for the benefits and risks associated with the medium to long term use ( $\geqslant 12$ weeks) of montelukast as add-on therapy to ICS in asthmatic adolescents and adults compared with ICS monotherapy or other treatment options recommended by guidelines. ${ }^{67}$ As montelukast is approved in Europe only for the treatment of mild to moderate asthma, this review only included studies in 
appropriate patients, and focused on outcomes relevant to patients, such as disease related symptoms and quality of life.

\section{METHODS}

The German Institute for Quality and Efficiency in Health Care This systematic review formed part of a health technology assessment of montelukast carried out by the German Institute for Quality and Efficiency in Health Care (Institut für Qualität und Wirtschaftlichkeit im Gesundheitswesen, IOWiG). The full (German language) report is available on the institute's website. ${ }^{14}$ The responsibilities and methodological approach of IOWiG are described in its methods paper. ${ }^{15}$

\section{Search strategy}

We searched MEDLINE (1966 to November 2006), EMBASE (1980 to November 2006) and the Cochrane Central Register of Controlled Trials (CENTRAL, November 2006) for randomised controlled trials (RCTs) using a comprehensive search strategy including the following keywords: asthma, bronchospasm, bronchoconstriction, leucotriene antagonist, antileucotriene, montelukast and singulair. Details of the full search strategy have been described elsewhere. ${ }^{14}$ The Cochrane Database of Systematic Reviews, the Database of Abstracts of Reviews of Effects and the Cochrane HTA Database were searched for relevant secondary publications. We also reviewed the references cited by the publications identified to obtain details of further studies. Clinical trial registries and study results databases available on the internet were also screened, as well as the websites of the European Medicines Agency and US Food and Drug Administration. ${ }^{11}{ }^{16}$ Moreover, the pharmaceutical companies producing montelukast (MSD Sharp and Dohme $\mathrm{GmbH}$ (MSD), Haar, Germany) or the active comparator used in the studies identified (salmeterol; GlaxoSmithKline (GSK), Munich, Germany) were asked to supply additional unpublished data.

\section{Study selection}

We included all publications that presented original data from RCTs if they fulfilled the following criteria: investigation of montelukast as add-on therapy to ICS in adults and adolescents ( $\geqslant 12$ years) with mild to moderate asthma; language of publication: English, German, Dutch, French, Spanish or Portuguese; evaluation of at least one of the following predefined outcomes: asthma symptoms, exacerbations with or without emergency treatment, hospitalisation and/or outpatient treatment, adverse events, activities of daily living, disease related quality of life, treatment satisfaction, physical capacity, asthma related mortality and total mortality. As asthma is a chronic condition, short term trials ( $<12$ weeks) were excluded. Although guidelines recommend 24 week trials to evaluate the effects of long term treatment, we also included medium term trials with a study period $\geqslant 12$ weeks in order to perform separate analyses to assess the effect of study duration.

Relevant publications retrieved from the primary literature search were identified independently by two reviewers (SJ, AM); firstly, by perusal of the study titles and abstracts to exclude evidently irrelevant publications, and secondly, by assessing the full texts of the remaining potentially relevant publications. The classification of the trials (relevant or not relevant) was subsequently discussed with BW, UG and TK, and any disagreement was settled by consensus.

As the review aimed to investigate montelukast in patients with mild to moderate asthma, trials in patients with severe asthma were excluded. It was originally planned to evaluate asthma severity using the definitions provided in the individual trials. However, this approach proved to be impossible, because information on asthma severity was insufficient in most publications. As a consequence, the proportion of patients with severe asthma (defined as forced expiratory volume in $1 \mathrm{~s}$ $\left(\mathrm{FEV}_{1}\right)$ per cent predicted $\leqslant 60 \%$ at baseline) was estimated from available $\mathrm{FEV}_{1} \%$ predicted data, and subsequently studies with more than $20 \%$ of patients with severe asthma were excluded from the review. To investigate the impact of this exclusion, a sensitivity analysis was conducted considering the results of trials in patients with severe asthma, and the conclusions of the review were reassessed.

\section{Data extraction and validity assessment}

Data extraction and quality assessment of the trials were conducted according to the methods of the IOWiG. ${ }^{15}$ Information and data from publications were supplemented by publicly available reports from study registries and unpublished study reports provided by MSD and GSK (table 1). Firstly, data were extracted by two of the authors (SJ, AM) using standardised extraction forms. Secondly, the consistency of data within the publication and with additional data sources such as the corresponding study report was assessed. The third step was a global appraisal of the study and publication quality based on the following quality criteria: characteristics of the study design, appropriate randomisation and allocation concealment, blinding of patients and investigators, sample size estimation, complete description of dropouts and appropriate application of the intention to treat principle.

Trials were then classified using the following quality categories: "no deficiencies" (study meets all quality criteria); "minor deficiencies" (deficiencies exist that do not affect the main conclusion); and "major deficiencies" (deficiencies exist that challenge the main conclusion).

\section{Methods of quantitative data synthesis}

Results for each of the predefined outcomes were compared between studies. If feasible and meaningful, data were pooled by means of meta-analyses. Effect measures were reported as relative risks (for binary data). A fixed effect model was used primarily to calculate a pooled effect estimate. As $\mathrm{I}^{2}$ as a measure of heterogeneity of effect sizes between studies ${ }^{17}$ was 0 in all pooled analyses presented in this article, fixed effect models were used. Statistical significance was assumed for $\mathrm{p}<0.05$.

\section{RESULTS \\ Trial flow}

Of 1637 potentially relevant abstracts, 12 studies fulfilled the inclusion criteria. In addition, one relevant study report was identified (fig 1).

\section{Study characteristics}

Table 1 shows the main characteristics of the studies included. In most studies, the mean age of participants ranged from 38 to 45 years. Treatment duration ranged from 12 to 48 weeks. The number of patients included per study varied between 30 and 1490. Mean $\mathrm{FEV}_{1}$ at baseline was between $70 \%$ and $99 \%$ predicted.

Three types of protocols were used: (1) montelukast as add-on therapy to constant dose ICS versus constant dose ICS monotherapy (with or without placebo) ${ }^{18-20}$; (2) montelukast 
Table 1 Characteristics of trials included

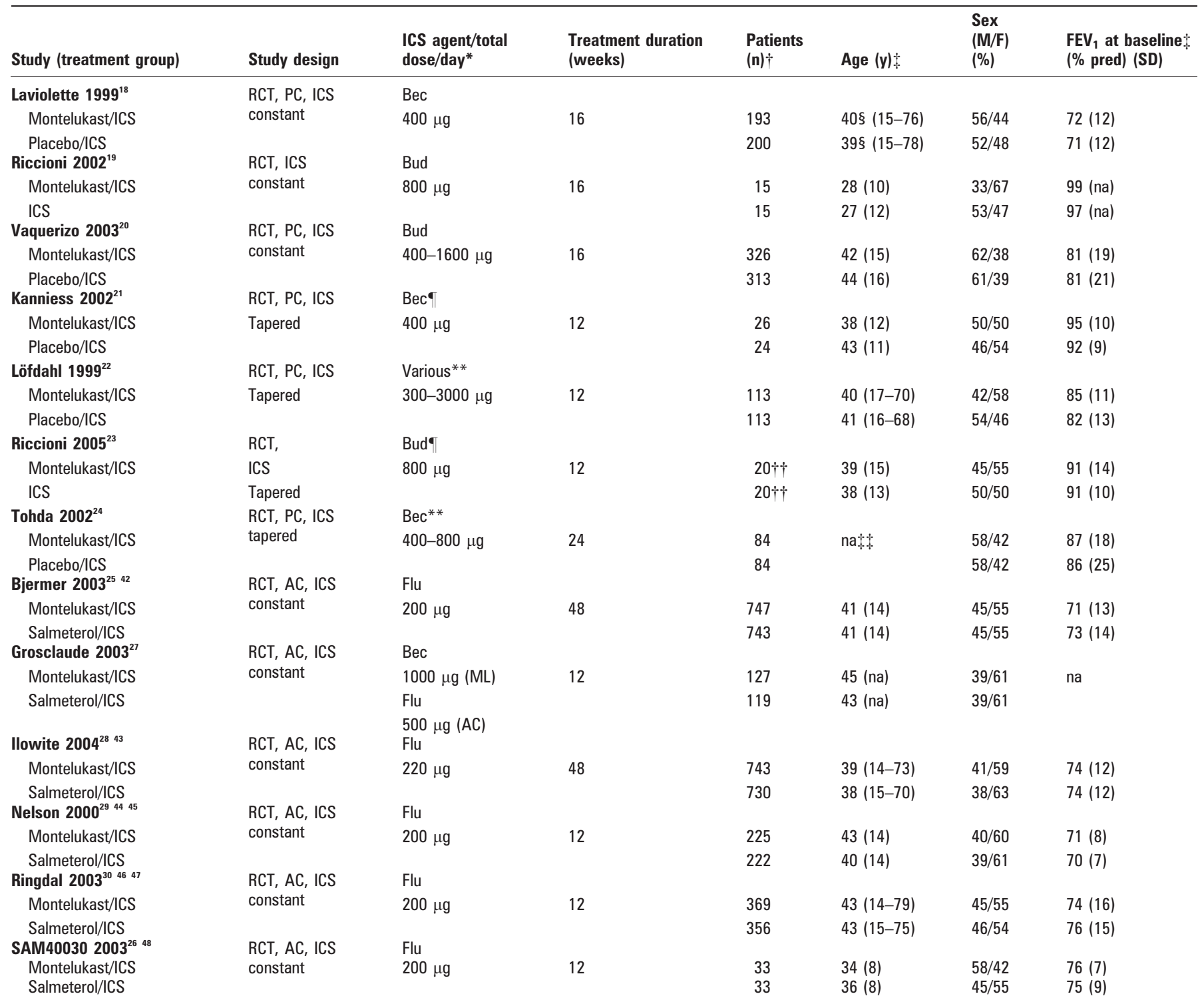

*In each treatment group (unless otherwise stated); †number of patients analysed for baseline data; $t$ mean (SD or range); $\S$ median; $\uparrow$ tapered according to protocol: dose halved after 6 weeks ${ }^{21}$; dose halved after 4,8 and 12 weeks ${ }^{23} ;{ }^{* *}$ tapered according to clinical symptoms; † †number of patients who completed the study; and $+*$ in the publication, the number of patients per age cohort is given.

References $42-44$ and 46 refer to unpublished study reports.

AC, active controlled (salmeterol); Bec, beclamethasone; Bud, budesonide; FEV 1 , forced expiratory volume in 1 s; Flu, fluticasone; ICS, inhaled corticosteroids; ML, montelukast; na, not available; PC, placebo controlled; RCT, randomised controlled trial.

as add-on therapy to tapered doses of ICS versus tapered doses of ICS monotherapy (with or without placebo) ${ }^{21-24}$; (3) montelukast versus salmeterol as add-on therapy to constant dose ICS. ${ }^{25-30}$

In all studies, montelukast $10 \mathrm{mg}$ was given as add-on therapy to ICS. Steroid regimens (dosage and agent) varied in the trials investigated. In the studies with tapered doses, ICS were reduced either according to a predefined protocol ${ }^{21}{ }^{23}$ or according to clinical asthma scores. ${ }^{22}{ }^{24}$ In five active controlled studies, addition of montelukast to constant dose fluticasone 100-250 $\mu \mathrm{g}$ twice daily was compared with the addition of salmeterol $50 \mu \mathrm{g}$ twice daily. ${ }^{25-30}$ In the Grosclaude study, ${ }^{27}$ constant dose beclomethasone was administered in the montelukast group while fluticasone was used in the salmeterol group. In three studies, ${ }^{26}{ }^{27} 29$ salmeterol and fluticasone were administered as a fixed combination.
In all studies, there was a run-in phase of 1-7 weeks, and in some studies all patients were switched to the same ICS agent during this phase.

In general, rescue $\beta_{2}$ agonists were permitted; however, in two studies, this was not clearly described. ${ }^{23} 25$

Table 2 summarises the methodological quality of the trials: six trials had minor or no deficiencies; seven trials failed to show sufficient methodological quality to draw a conclusion about the results of these studies. Common shortcomings included deficiencies in the randomisation and allocation concealment process, missing sample size calculations and incomplete description of dropouts. Furthermore, nearly half of the studies lacked, or had inappropriate application of, an intention to treat analysis. A double blind design was used except for three trials, ${ }^{19} 2327$ two of which had an open label design and one whose design was unclear. As the extent of potential bias in 


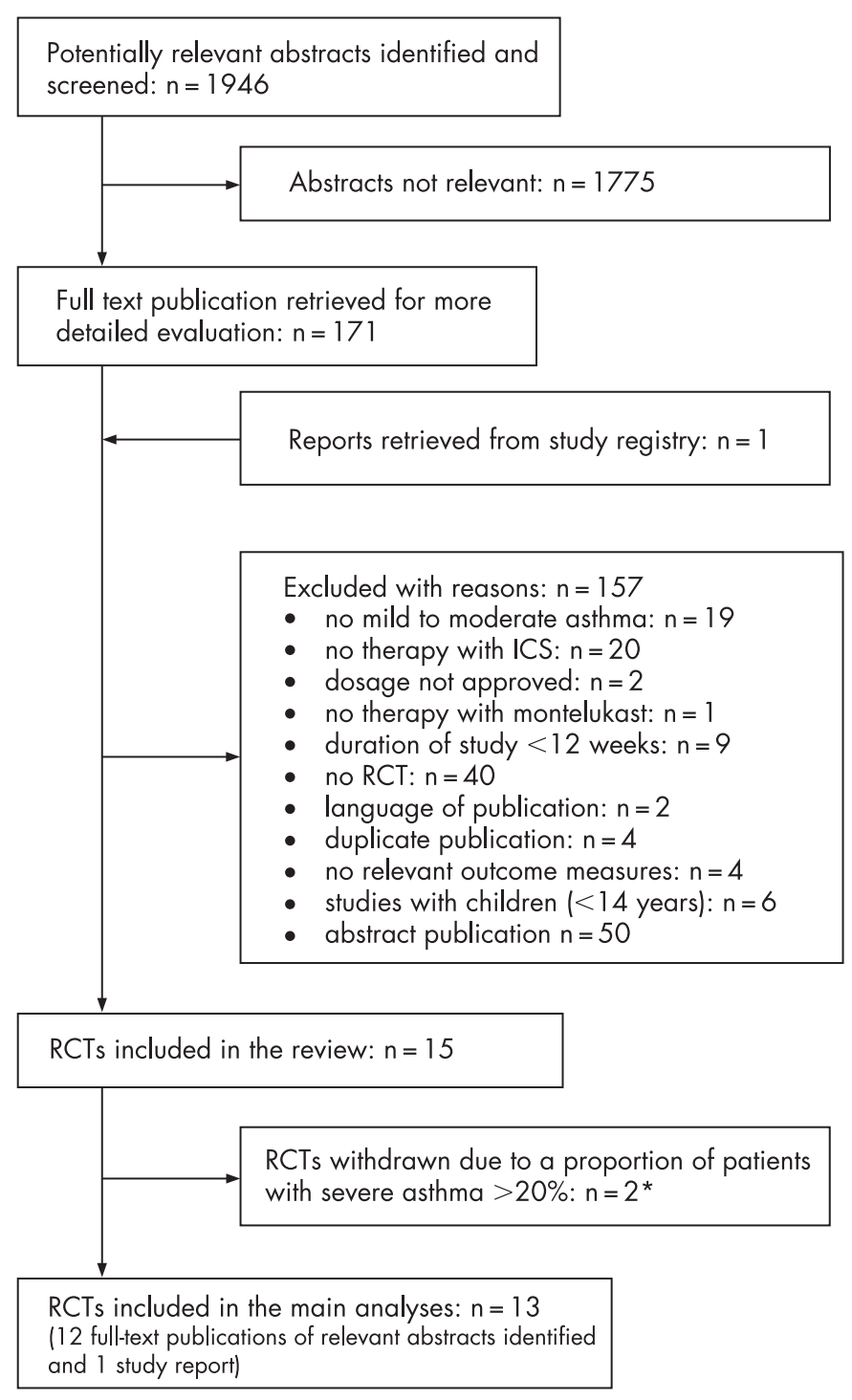

Figure 1 Flow diagram of trial selection. * Sensitivity analyses including these studies ${ }^{32}{ }^{33}$ were performed. ICS, inhaled corticosteroids; $\mathrm{RCT}$, randomised controlled trial.

open studies cannot be estimated, open studies were allocated to the category "major deficiencies".

\section{Quantitative data synthesis}

The outcome measures investigated were not consistent between studies (tables 3,4 ). In one of the studies, one death was reported ("death with severe asthma attack" after 15 days of treatment with salmeterol/fluticasone).$^{25}$

\section{Montelukast as add-on therapy to constant dose ICS versus constant dose ICS monotherapy}

Only one study ${ }^{20}$ was of good methodological quality. Overall, symptom control was significantly better with montelukast, as shown by asthma symptom scores ${ }^{18}$ the number of asthma-free days ${ }^{20}$ or nocturnal awakenings ${ }^{18}{ }^{20}$ (table 3 ). Exacerbations were also significantly reduced with montelukast. ${ }^{18} 20$ However, regarding quality of life and treatment satisfaction, there were no significant differences between treatment groups. ${ }^{18} 20$ The addition of montelukast did not result in higher overall adverse event rates or increased withdrawal rates as a result of adverse events. There were no data on hospitalisation and additional visits to physicians available.

\section{Montelukast as add-on therapy to tapered doses of ICS versus} tapered doses of ICS monotherapy

Of the four studies assessing the ICS sparing potential of montelukast, only the study of Löfdahl et al fulfilled all of the quality criteria. ${ }^{22}$ Furthermore, this study was the only one that included a dose optimisation period in the run-in phase. The "last tolerated dose" of ICS was the primary outcome measure, and addition of montelukast allowed a significant reduction in ICS baseline dose (last tolerated dose $526 \mu \mathrm{g} /$ day (montelukast/ ICS) vs $727 \mu \mathrm{g} /$ day (ICS only); $\mathrm{p}=0.046$ ).

In the study by Kanniess and colleagues, ${ }^{21}$ daytime symptoms after ICS dose reduction were not altered in the ICS monotherapy group but significantly reduced by montelukast (data not shown, $\mathrm{p}<0.05$ ).

Montelukast versus long acting $\beta_{2}$ agonists (salmeterol) as add-on therapy to constant dose ICS

With regard to asthma symptoms and exacerbations, most of the active controlled trials (of which two-thirds were of good or acceptable methodological quality) showed that patients benefit more from salmeterol than from montelukast as add-on therapy (table 4). In a meta-analysis of the 12 week trials, salmeterol was significantly superior regarding the proportion of patients with exacerbations (RR 2.03, 95\% CI 1.23 to 3.37, p=0.006) (fig 2). However, in the respective analysis of the 48 week trials, the difference between the montelukast/ICS and salmeterol/ ICS groups was not significant (fig 2). One 48 week trial25 demonstrated the non-inferiority of montelukast compared with salmeterol with regard to exacerbations, while in the other, ${ }^{28}$ non-inferiority was not shown.

The rates for hospitalisation and emergency treatment were similar between groups whereas the data on additional visits to physicians were inconclusive (table 4). In the studies of Ilowite and colleagues ${ }^{28}$ and Ringdal and colleagues, ${ }^{30}$ quality of life and treatment satisfaction, respectively, were evaluated significantly more positively by patients in the salmeterol group. In contrast, Bjermer and colleagues ${ }^{25}$ found no difference in quality of life between treatment groups.

The overall adverse event rates were comparable. However, separate meta-analyses of 12 and 48 week trials indicated that salmeterol had a less favourable long term safety profile; the pooled data of the Bjermer and Ilowite studies ${ }^{25} 28$ showed a significantly higher rate of serious adverse events in the salmeterol group ( $R R$ $0.68,95 \%$ CI 0.49 to $0.94, p=0.021$ ) (fig 3 ).

\section{Sensitivity analysis}

Two studies were excluded from the main analysis because they included more than $20 \%$ of patients with severe asthma (estimation of proportion of patients with $\mathrm{FEV}_{1} \%$ predicted $\leqslant 60 \%$ based on mean and $\mathrm{SD}$ of $\mathrm{FEV}_{1} \%$ predicted at baseline). ${ }^{31}{ }^{32}$ The study by Price and colleagues ${ }^{31}$ investigated montelukast/budesonide $800 \mu \mathrm{g}$ versus budesonide $1600 \mu \mathrm{g}$. Comparable outcomes were observed. Thus the Price study confirms an ICS sparing potential of montelukast; this was also reported by Löfdahl and colleagues. ${ }^{22}$ The study by Fish and colleagues, ${ }^{32}$ which described a pooled analysis of two 12 week studies comparing montelukast/ICS and salmeterol/ICS, also showed better symptom control in patients receiving salmeterol/ICS. When the data from the Fish study were included in the meta-analysis of serious adverse events in the 12 week 
Table 2 Quality of trials included

\begin{tabular}{|c|c|c|c|c|c|c|}
\hline Study & $\begin{array}{l}\text { Randomisation/ } \\
\text { allocation } \\
\text { concealment } \\
\text { appropriate }\end{array}$ & Blinding* & $\begin{array}{l}\text { Sample size } \\
\text { calculation } \\
\text { appropriate }\end{array}$ & $\begin{array}{l}\text { ITT analysis } \\
\text { appropriate }\end{array}$ & $\begin{array}{l}\text { Dropouts (\% } \\
\text { of patients) } \\
\mathrm{ML} / \text { control }\end{array}$ & $\begin{array}{l}\text { Quality } \\
\text { domain }\end{array}$ \\
\hline \multicolumn{7}{|c|}{ Montelukast+ICS vs ICS monotherapy } \\
\hline Laviolette $1999^{18}$ & Yes/yes & Yes & Incomplete $\uparrow$ & Unclear & $8 / 11$ & 3 \\
\hline Riccioni $2002^{19}$ & Unclear/unclear & No & na & Yes & na & $3 \$$ \\
\hline Vaquerizo $2003^{20}$ & Yes/yes & Yes & Yes & Yes & $10 / 10$ & 1 \\
\hline Kanniess $2002^{21}$ & Unclear/unclear & Yes & Incomplete $\uparrow$ & Yes & $12 / 8$ & $3 \$$ \\
\hline Löfdahl $1999^{22}$ & Yes/yes & Yes & Incomplete $\uparrow$ & Yes & $16 / 27$ & 1 \\
\hline Riccioni $2005^{23}$ & Unclear/unclear & Unclear & No & No & $9 / 13$ & $3 \%$ \\
\hline Tohda $2002^{24}$ & Unclear/unclear & Yes & Yes & No & $6 / 7$ & $3 t$ \\
\hline \multicolumn{7}{|c|}{ Montelukast+ICS vs salmeterol+ICS } \\
\hline Bjermer $2003^{25} 42$ & Yes/yes & Yes & Yes & Yes & $17 / 15$ & 1 \\
\hline Grosclaude $2003^{27}$ & Unclear/unclear & No & na & No & $13 / 6$ & 3 \\
\hline llowite $2004^{28} 43$ & Yes/unclear & Yes & Yes & No & $17 / 16 \S$ & 2 \\
\hline Nelson $2000^{2944} 45$ & Yes/yes & Yes & Yes & Yes & $13 / 11$ & 1 \\
\hline Ringdal $2003^{30} 4647$ & Yes/unclear & Yes & Yes & No & $10 / 5$ & 3 \\
\hline SAM40030 $2003^{2648}$ & Yes/yes & Yes & $\mathrm{No}^{* *}$ & Yes & $12 / 27$ & $1^{* *}$ \\
\hline
\end{tabular}

studies, the overall result of the analysis did not change ( $R R$ 1.17; $95 \%$ CI 0.55 to 2.47). However, inclusion of these data in the meta-analysis of exacerbations resulted in a non-significant difference between treatment groups (RR 1.41; 95\% CI 0.98 to 2.02) compared with a significant difference in favour of salmeterol observed in the meta-analysis excluding patients with severe asthma (fig 2).

\section{DISCUSSION}

This systematic review evaluated add-on therapy in patients with asthma who remained symptomatic on ICS. In all included studies, ICS dosage was sufficient considering the flat dose-response of ICS, with most of the therapeutic benefit with a total daily dose of 100-250 $\mu \mathrm{g}$ for fluticasone ${ }^{49}$ and $400 \mu \mathrm{g}$ for budesonide $^{50}$ or equivalence, respectively, which is of particular importance when investigating secondline controller therapy. Data from the studies examined in this systematic review indicate a clinical advantage of montelukast/ICS versus ICS monotherapy. In contrast, montelukast/ICS was clinically less effective than salmeterol/ICS, at least in the medium term (12 weeks). Pooled data of the active controlled 48 week trials showed that significantly more serious adverse events occurred in patients receiving salmeterol/ICS.

Montelukast as add-on therapy to ICS versus ICS monotherapy Overall, montelukast as add-on therapy to ICS was more effective with regard to clinical outcomes than ICS monotherapy, although this finding was not reflected by an improvement in quality of life or treatment satisfaction. The ICS sparing potential of montelukast was demonstrated in a confirmative analysis in one study of good methodological quality. However, the other studies investigating this question were of poorer methodological quality, and data on clinical outcomes were scarce. Furthermore, there was variation in the design of the trials with tapered doses of ICS (different tapering protocols and baseline doses of ICS, lack of a dose optimisation period prior to randomisation), which made pooling of the data and interpretation of study results difficult. Ideally, future studies on ICS sparing effects of LTRA should use comparable study protocols and include a prolonged run-in period that optimises the ICS dose to the minimum effective dose. In addition, ICS doses should be tapered according to clinical asthma scores.

\section{Montelukast versus long acting beta agonists (salmeterol) as add-on therapy to ICS}

The efficacy of montelukast may be explained by its antiinflammatory effect, which is the hallmark of asthma therapy. ${ }^{33}$ The importance of reducing eosinophilic inflammation was demonstrated in several studies. ${ }^{34-36}$ Despite the fact that this therapeutic principle seems to be addressed with montelukast, its impact on symptom reduction and quality of life is weaker compared with LABA, at least in the medium term.

However, much controversy currently surrounds the use of LABA. ${ }^{16}$ In our review, the increased rate of long term serious adverse events in the LABA group deserves particular attention, as not only the SMART study ${ }^{37}$ but also a recent meta-analysis ${ }^{38}$ showed an increase in asthma related deaths in patients using LABA. However, according to exploratory subgroup analyses, ${ }^{48}$ the increase in asthma related deaths is mainly in those patients who are taking LABA without ICS. Following the SMART study, the US Food and Drug Administration issued a warning about the increased risk of adverse outcomes with LABA. ${ }^{16}$

Interestingly, in the discussion section of the Cochrane review comparing LTRA and LABA as add-on therapy to ICS, the authors point to the wide confidence interval for serious adverse events, which included the possibility of an increased risk of such events in the LABA group. ${ }^{10}$ This trend became statistically significant in our subanalysis of long term trials. A negative feedback mechanism of the $\beta$ adrenergic system as an adaptive response to the stimulation of receptors is suspected of being responsible for the worsening of asthma control. $^{39}$ 
Table 3 Effects of montelukast as add-on therapy to ICS versus ICS monotherapy

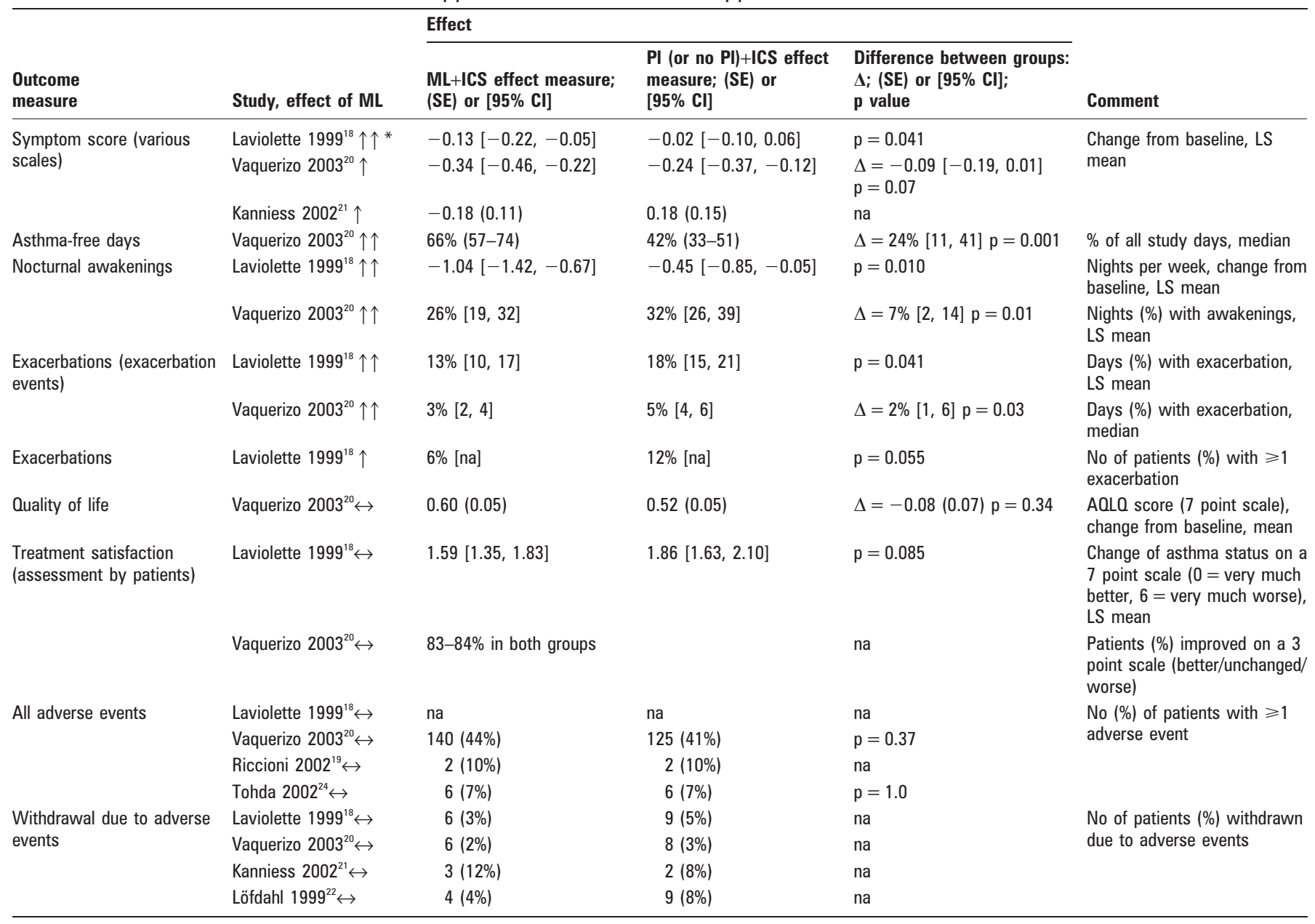

\footnotetext{
${ }^{*}$ Confirmative analysis.

$\uparrow \uparrow$ Montelukast better than placebo (with statistical significance); $\uparrow$ montelukast better than placebo (without statistical significance); $\leftrightarrow$ montelukast comparable with placebo; $\downarrow$ montelukast worse than placebo (without statistical significance); and $\downarrow \downarrow$ montelukast worse than placebo (with statistical significance).

AOLO, Asthma Quality of Life Questionnaire; ICS, inhaled corticosteroids; LS mean, least square mean; ML, montelukast; na, not available; PI, placebo; SE, standard error.
}

In the light of the current safety discussion, ${ }^{38}$ montelukast may be a treatment alternative in asthma that is suboptimally controlled with ICS. The disadvantage of slower symptom relief with montelukast ${ }^{27} 2830$ may be counterbalanced by possibly better long term safety. In consequence, treatment regimens recommended in guidelines should be re-discussed, taking the risk-benefit profile of montelukast and other treatment options into account. In this regard, concerns may be raised about a potential link between leucotriene receptor antagonist use for asthma and the onset of Churg-Strauss syndrome, a rare disease with a poorly understood pathogenesis.

Long term trials are needed for a conclusive evaluation of the long term efficacy and safety of various alternative controller medications in patients with mild to moderate asthma. In those trials, possible efficacy relevant aspects such as patient age, comorbidities or ethnic group should be considered for study design and analysis. Also, patient acceptance and compliance for oral compared with inhaled preparations should be assessed in future studies as these factors may have a relevant impact on the difference between medium and long term studies.

\section{Strengths and limitations}

The value of this review is strengthened by the restriction to studies of at least 12 weeks' duration. This selection criterion avoids bias in favour of short term effects when pooling data. At the same time, inclusion of 12 week trials allowed an assessment of the effect of study duration.

Inclusion of trials with different clinical outcome measures could be seen as a limitation of this review. At first sight, this approach led to a heterogeneous pool of studies; however, overall, the findings from this pool showed consistent trends.

The outcome measures included in our review were not necessarily defined as primary outcomes in the original studies. Secondary outcome measures may be more prone to reporting bias-that is, it is possible that only outcomes showing significant treatment differences are reported in published articles, resulting in an overestimation of treatment effects..$^{40}$ However, for the active controlled studies, we were provided with unpublished study reports describing all of the results for primary and secondary outcomes in four of five studies. Thus at least the comparison of montelukast and salmeterol as add-on therapy is less likely to be prone to reporting bias.

Inclusion of both efficacy and safety outcomes turned out to be the strength of our review, as we detected comparable efficacy regarding the risk for exacerbations but significantly higher rates of serious adverse events in patients receiving LABA in the long term active controlled trials. This broad approach may be an explanation as to why this finding was not detected in previous reviews. ${ }^{10}{ }^{12} \mathrm{Sin}$ et al included trials with a follow-up 
Table 4 Effects of montelukast versus salmeterol as add-on therapy to ICS

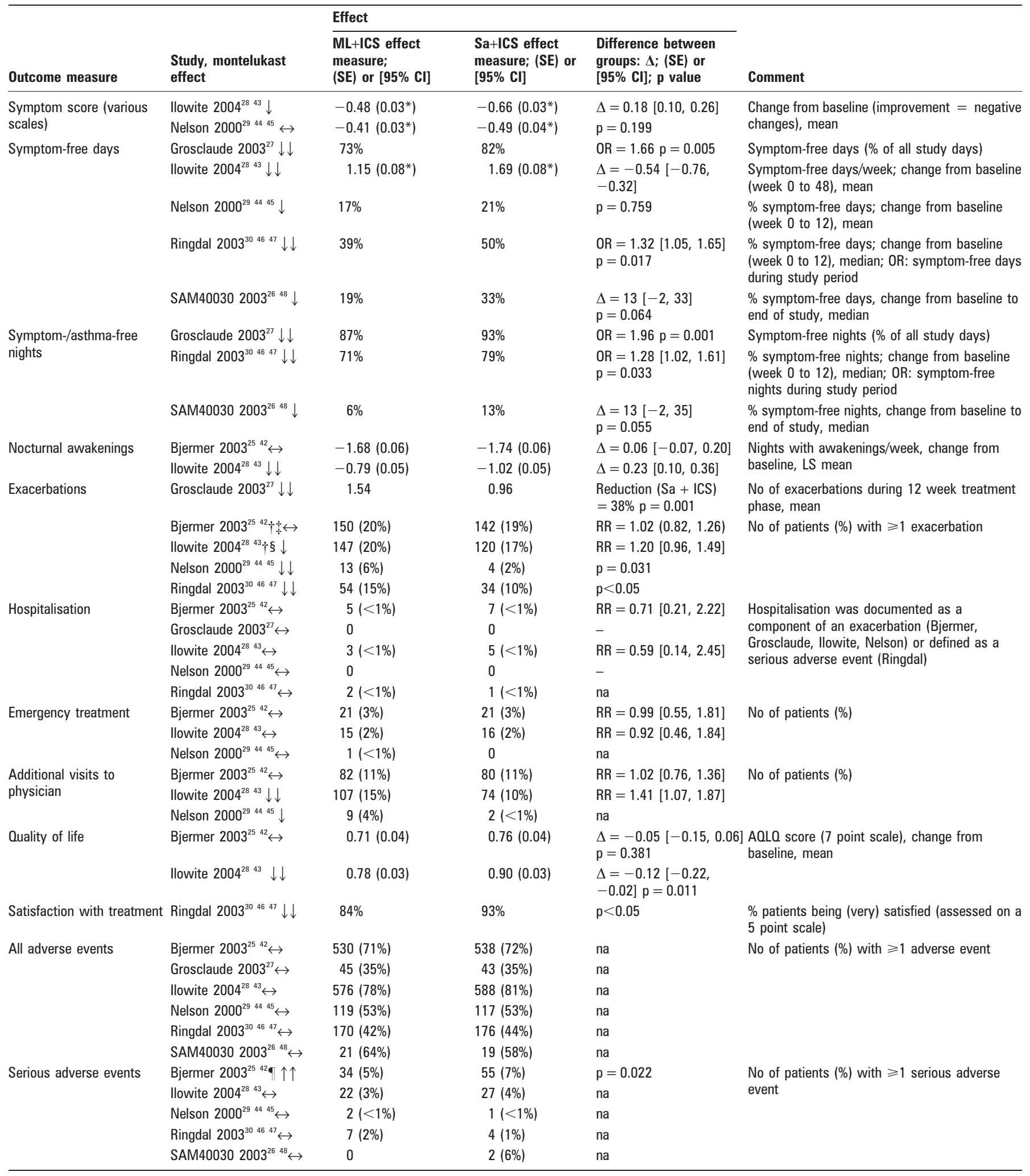


Table 4 Continued

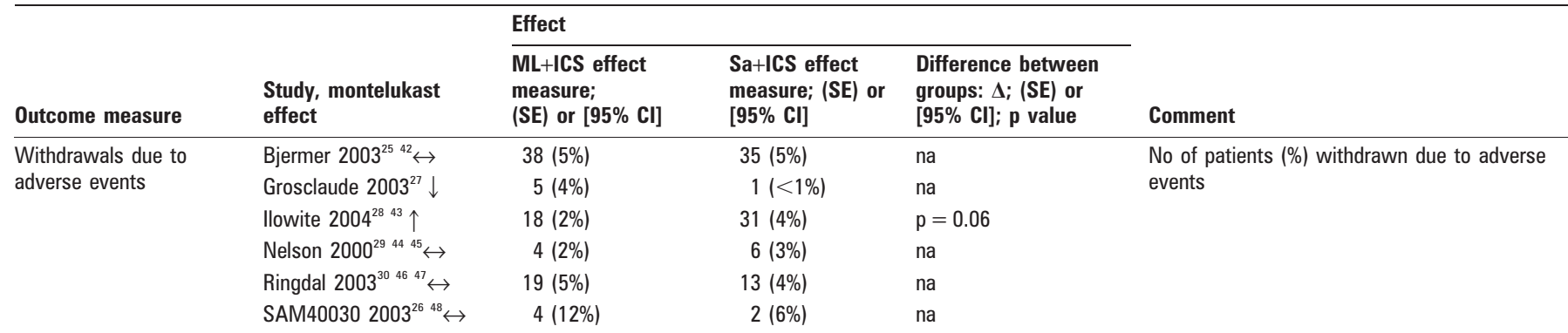

\begin{abstract}
$\uparrow \uparrow$ Montelukast better than salmeterol (with statistical significance); $\uparrow$ montelukast better than salmeterol (without statistical significance); $\leftrightarrow$ montelukast comparable to salmeterol; $\downarrow$ montelukast worse than salmeterol (without statistical significance); and $\downarrow \downarrow$ montelukast worse than salmeterol (with statistical significance).

${ }^{*}$ Reported as SD in publication; †confirmatory analysis; †non-inferiority trial; non-inferiority demonstrated; §non-inferiority trial; non-inferiority not demonstrated; and $\uparrow$ death of one patient ("death with a severe asthma attack") in the salmeterol/fluticasone group 15 days after the start of treatment, reported by the investigator as being possibly related to the study drug.

AQLQ, Asthma Quality of Life questionnaire; ICS, inhaled corticosteroids; LS mean, least square mean; ML, montelukast; na, not available; RR, relative risk; Sa, salmeterol; SE, standard error.
\end{abstract}

period of at least 3 months but focused solely on the exacerbation rate as a clinical outcome. ${ }^{12}$ The Cochrane reviews also used a broad approach but permitted studies with a minimum duration of 28 days. ${ }^{5} 10$

Clinical trials are often conducted in highly selective patient populations considering factors such as age, ethnic groups, comorbidities, asthma characteristics, etc. This must be taken into account when making conclusions on the basis of study results. In this regard, we cannot exclude preselection of patients, as reversibility of $\mathrm{FEV}_{1}$ was used as an inclusion criterion in the studies. Although $\mathrm{FEV}_{1}$ reversibility is one of the standard diagnostic criteria of asthma, ${ }^{6-8}$ it is possible that patients who were more likely to respond to LABA may have been selected, rather than asthma patients seen in normal clinical practice. Because of this preselection, the effects of LABA may have been overestimated. It should therefore be questioned whether reversibility of $\mathrm{FEV}_{1}$ is an appropriate inclusion criterion in trials evaluating LABA, and it should also be kept in mind that significant reversibility is difficult to attain in patients on controller therapy.

Studies including more than $20 \%$ of patients with severe asthma were not considered in this review. However, defining asthma severity is problematic, as it depends on the time point of the patient's assessment. Classification of asthma severity in studies is consequently difficult and, because of varying inclusion criteria, not comparable between studies. ${ }^{41}$ That is why we also included studies with a small proportion $(<20 \%)$ of patients with asthma classified as "severe". Two RCTs were excluded from the main analysis because of the large proportion of patients with severe asthma. Although the inclusion of patients with severe asthma in the meta-analysis of 12 week trials nullified the previous significant difference in favour of salmeterol regarding exacerbations, a systematic analysis of the effects of montelukast in patients with severe asthma would be needed to make any firm conclusion about the benefits of montelukast in this patient population.

\section{CONCLUSION}

The addition of montelukast to ICS improves control of mild to moderate asthma compared with ICS monotherapy. However, montelukast as add-on therapy to ICS is less effective than the addition of salmeterol with regard to most clinical outcomes, at least in the medium term. Because of the possibly better long term safety profile of montelukast compared with salmeterol,
Figure 2 Effect of montelukast/ICS versus salmeterol/ICS on the proportion of patients with at least one asthma exacerbation in 12 and 48 week trials. ICS, inhaled corticosteroid; RR, relative risk; n, patients with exacerbations; N, total number of patients.
12 week trials

\begin{tabular}{|c|c|c|c|c|c|c|c|}
\hline Study & $\begin{array}{c}\text { Montelukast } \\
\mathrm{n} / \mathrm{N}\end{array}$ & $\begin{array}{c}\text { Salmeterol } \\
\mathrm{n} / \mathrm{N}\end{array}$ & RR (fixed - & $\begin{array}{l}\text { antel-Haenszel) } \\
\% \mathrm{Cl}\end{array}$ & $\begin{array}{c}\text { Weight } \\
\%\end{array}$ & $\begin{array}{r}R \\
95^{\circ}\end{array}$ & $\begin{array}{l}\mathrm{R} \\
\% \mathrm{Cl}\end{array}$ \\
\hline $\begin{array}{l}\text { Nelson } 2000^{29} \\
\text { Ringdal } 2003^{30}\end{array}$ & $\begin{array}{l}13 / 225 \\
31 / 369\end{array}$ & $\begin{array}{r}4 / 222 \\
17 / 356\end{array}$ & & 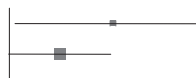 & $\begin{array}{l}18.88 \\
81.12\end{array}$ & $\begin{array}{l}3.21 \\
1.76\end{array}$ & $\begin{array}{l}(1.06,9.68) \\
(0.99,3.12)\end{array}$ \\
\hline Total $(95 \% \mathrm{Cl})$ & $44 / 594$ & $21 / 578$ & $\perp$ & 7 & 100.00 & 2.03 & $(1.23,3.37)$ \\
\hline
\end{tabular}

Heterogeneity: $Q=0.9, d f=1(p=0.343), 1^{2}=0 \%$

Overall effect: $Z$ score $=2.75(p=0.006)$

48 week trials

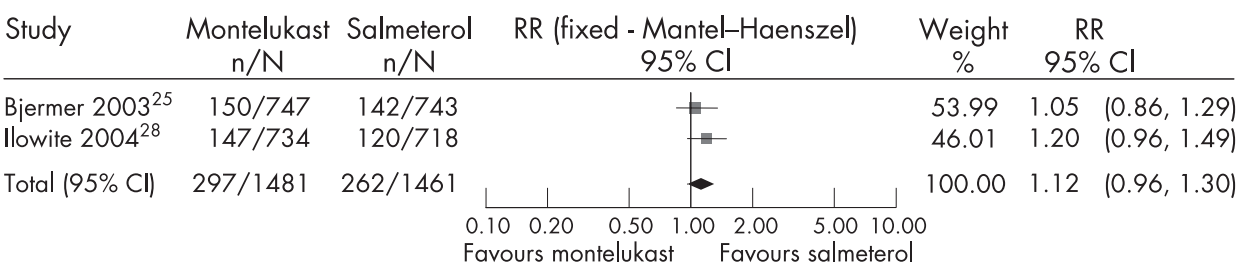

Heterogeneity: $Q=0.74, d f=1(p=0.390),\left.\right|^{2}=0 \%$

Overall effect: $Z$ score $=1.47(p=0.142)$ 
Figure 3 Serious adverse events with montelukast/ICS versus salmeterol/ICS in 12 and 48 week trials. ICS, inhaled corticosteroid; RR, relative risk; $n$, patients with exacerbations; $\mathrm{N}$, total number of patients.
12 week trials

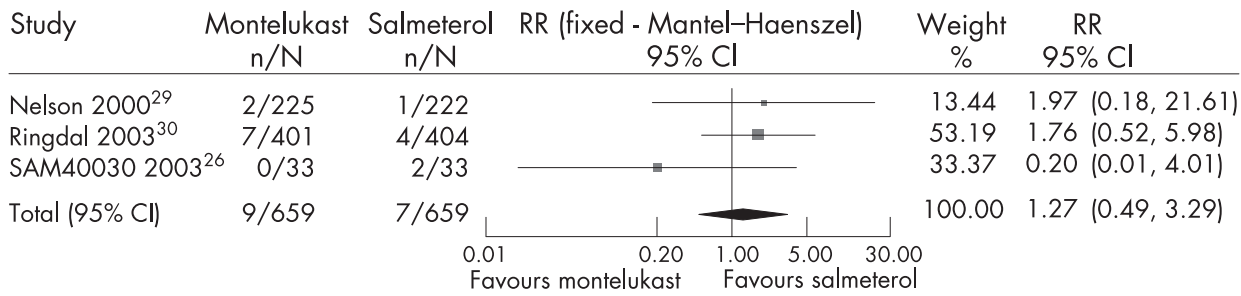

Heterogeneity: $Q=1.87, d f=2(p=0.393),\left.\right|^{2}=0 \%$

Overall effect: $Z$ score $=0.49(p=0.622)$

48 week trials

\begin{tabular}{|c|c|c|c|c|c|c|c|}
\hline Study & $\begin{array}{c}\text { Montelukast } \\
\mathrm{n} / \mathrm{N}\end{array}$ & $\begin{array}{c}\text { Salmeterol } \\
\mathrm{n} / \mathrm{N}\end{array}$ & $\begin{array}{r}\text { RR (fixed - Ma } \\
95^{\circ}\end{array}$ & $\begin{array}{l}\text { tel-Haenszel) } \\
6 \mathrm{Cl}\end{array}$ & $\begin{array}{c}\text { Weight } \\
\%\end{array}$ & $\begin{array}{r}R \\
95^{\circ} \\
\end{array}$ & $\begin{array}{l}\mathrm{R} \\
\% \mathrm{Cl}\end{array}$ \\
\hline $\begin{array}{l}\text { Biermer } 2003^{25} \\
\text { llowite } 2004^{28}\end{array}$ & $\begin{array}{l}34 / 747 \\
22 / 743\end{array}$ & $\begin{array}{l}55 / 743 \\
27 / 730\end{array}$ & $\Longrightarrow$ & & $\begin{array}{l}66.94 \\
33.06\end{array}$ & $\begin{array}{l}0.61 \\
0.80\end{array}$ & $\begin{array}{l}(0.41,0.93) \\
(0.46,1.39)\end{array}$ \\
\hline Total $(95 \% \mathrm{CI})$ & $56 / 1490$ & $82 / 1473$ & $\square$ & 1 & 100.00 & 0.68 & $(0.49,0.94)$ \\
\hline
\end{tabular}

Heterogeneity: $Q=0.56, d f=1(p=0.455),\left.\right|^{2}=0 \%$

Overall effect: $Z$ score $=-2.31(p=0.021)$ montelukast may be considered as an add-on treatment alternative in patients suboptimally controlled with ICS. These findings indicate that asthma treatment guidelines should be reassessed to clarify whether the current recommendations require modification.

Acknowledgements: The authors thank Elke Vervölgyi for contributing to the quality assessment of studies and Natalie McGauran for editorial support. Both contributors are employed by IOWiG

All authors conceived the protocol of this review, BW and TK performed the literature search; SJ and AM reviewed all citations for relevance; SJ, AM, BW and UG reviewed all included trials for methods and data extraction; BW and TK corresponded with pharmaceutical companies to obtain collaboration; UG did the statistical analyses; all authors commented on the final manuscript. $\mathrm{SJ}$ is the guarantor.

Funding: This work was supported by the Institute for Quality and Efficiency in Health Care (Institut für Qualität und Wirtschaftlichkeit im Gesundheitswesen, IOWiG)

Competing interests: None.

\section{REFERENCES}

1. Lewis RA, Austen KF, Soberman RJ. Leukotrienes and other products of the 5 lipoxygenase pathway. Biochemistry and relation to pathobiology in human diseases. N Engl J Med 1990;323:645-55.

2. Drazen JM, Israel E, O'Byrne PM. Treatment of asthma with drugs modifying the leukotriene pathway. N Engl J Med 1999:340:197-206.

3. Pizzichini E, Leff JA, Reiss TF, et al. Montelukast reduces airway eosinophilic inflammation in asthma: a randomized, controlled trial. Eur Respir J 1999;14:12-18.

4. Currie GP, Lipworth BJ. Bronchoprotective effects of leukotriene receptor antagonists in asthma: a meta-analysis. Chest 2002;122:146-50.

5. Ducharme FM. Inhaled glucocorticoids versus leukotriene receptor antagonists as single agent asthma treatment: systematic review of current evidence. BMJ 2003;326:621.

6. National Institute of Health. Global Initiative for Asthma-Global Strategy for Asthma Management and Prevention Update 2005. http://www.ginasthma.com/ Guidelineitem.asp??!1 = 2\&l2 = 1 \&intld = 60 (accessed 4 November 2007).

7. ÄZ2. Nationale Versorgungsleitlinie Asthma (National Guideline for Asthma Care). http://www.versorgungsleitlinien.de/themen/asthma/langfassung/index_html (accessed 4 November 2007).

8. British Thoracic Society. The BTS/SIGN 2004 Update of British Guideline on the Management of Asthma. http://www.enterpriseportal2.co.uk/filestore/bts/ asthmaupdatenov05.pdf (accessed 4 November 2007).

9. Ducharme FM. Anti-leukotrienes as add-on therapy to inhaled glucocorticoids in patients with asthma: systematic review of current evidence. BMJ 2002;324:1545.

10. Ram FS, Cates CJ, Ducharme FM. Long-acting beta2-agonists versus antileukotrienes as add-on therapy to inhaled corticosteroids for chronic asthma. Cochrane Database Syst Rev. Chichester: Wiley InterScience, 2005:CD003137.
11. European Medicines Agency EMEA. 2006. http://www.emea.eu.int/pdfs/human/ ewp/292201en.pdf\#search = \%22emea\%20asthma\%20study\%22 laccessed 4 November 2007)

12. Sin DD, Man J, Sharpe $H$, et al. Pharmacological management to reduce exacerbations in adults with asthma: a systematic review and meta-analysis. JAMA 2004;292:367-76.

13. Kankaanranta $\mathbf{H}$, Lahdensuo A, Moilanen $\mathbf{E}$, et al. Add-on therapy options in asthma not adequately controlled by inhaled corticosteroids: a comprehensive review. Respir Res 2004:5:17

14. IOWIG. Leukotrien-Rezeptor-Antagonisten bei Patienten mit Asthma bronchiale (Leukotriene receptor antagonists in patients with asthma bronchiale), 2006. http:// www.iqwig.de/download/A05-14 Abschlussbericht Leukotrien-ReceptorAntagonisten bei Asthma bronchiale.pdf (accessē 19 November 2007).

15. IOWIG. Methods. Version 09112005 ed. Institute for Quality and Efficiency in Health Care, 2005.http://www.iqwig.de/download/Methoden_10WiG_V-2-0.pdf (accessed 19 November 2007).

16. US Food and Drug Administration FDA, 2006. http://www.fda.gov/CDER/DRUG/ InfoSheets/HCP/salmeterolHCP.pdf\#search = \%22fda\%20long-acting\%20smart\%22 (accessed 4 November 2007).

17. Egger M, Smith GD, Altman DG. Systematic reviews in health care-Meta-analysis in context. London: BMJ Publishing, 2001.

18. Laviolette $\mathbf{M}$, Malmstrom K, Lu S, et al. Montelukast added to inhaled beclomethasone in treatment of asthma. Am J Respir Crit Care Med 1999;160:18628.

19. Riccioni G, Ballone E, D’Orazio N, et al. Effectiveness of montelukast versus budesonide on quality of life and bronchial reactivity in subjects with mild-persistent asthma. Int J Immunopathol Pharmacol 2002;15:149-55.

20. Vaquerizo MJ, Casan P, Castillo J, et al. Effect of montelukast added to inhaled budesonide on control of mild to moderate asthma. Thorax 2003;58:204-10.

21. Kanniess F, Richter K, Janicki S, et al. Dose reduction of inhaled corticosteroids under concomitant medication with montelukast in patients with asthma. Eur Respir J 2002:20:1080-7.

22. Löfdahl CG, Reiss TF, Leff JA, et al. Randomised, placebo controlled trial of effect of a leukotriene receptor antagonist, montelukast, on tapering inhaled corticosteroids in asthmatic patients. BMJ 1999;319:87-90.

23. Riccioni G, Vecchia RD, Castronuovo $\mathrm{M}$, et al. Tapering dose of inhaled budesonide in subjects with mild-to-moderate persistent asthma treated with montelukast: a 16week single-blind randomized study. Ann Clin Lab Sci 2005;35:285-9.

24. Tohda Y, Fujimura M, Taniguchi $\mathrm{H}$, et al. Leukotriene receptor antagonist, montelukast, can reduce the need for inhaled steroid while maintaining the clinical stability of asthmatic patients. Clin Exp Allergy 2002;32:1180-6.

25. Bjermer L, Bisgaard H, Bousquet J, et al. Montelukast and fluticasone compared with salmeterol and fluticasone in protecting against asthma exacerbation in adults: one year, double blind, randomised, comparative trial. BMJ 2003;327:891.

26. GlaxoSmithKline. A phase IV, multicentre, randomised, double-blind, single dummy, parallel group study to compare the anti-inflammatory action of Seretide ${ }^{\mathrm{TM}} 50 \mathrm{MDI}$ b.d. with Flixotide ${ }^{T M} 50$ ug MDI b.d. plus montelukast 10 mg o.d. for 12 weeks, in adults with mild to moderate asthma who are currently taking inhaled corticosteroids but have a requirements for further therapy_-Study SAM40030 (SOLTA - Seretide Or 
addition of a Leukotriene antagonist in the Treatment of Asthma). Glaxo Smith Kline Report No SAM40030R 2004.

27. Grosclaude M, Cerruti JL, Delannay B, et al. A fixed combination of fluticasone and salmeterol permits better control of asthma than a beclomethasone dipropionate and montelukast combination. Allergy Immunol (Paris) 2003;35:356-62.

28. Ilowite J, Webb R, Friedman B, et al. Addition of montelukast or salmeterol to fluticasone for protection against asthma attacks: a randomized, double-blind, multicenter study. Ann Allergy Asthma Immunol 2004;92:641-8.

29. Nelson HS, Busse WW, Kerwin E, et al. Fluticasone propionate/salmeterol combination provides more effective asthma control than low-dose inhaled corticosteroid plus montelukast. J Allergy Clin Immunol 2000;106:1088-95.

30. Ringdal N, Eliraz A, Pruzinec $\mathrm{R}$, et al. The salmeterolffluticasone combination is more effective than fluticasone plus oral montelukast in asthma. Respir Med 2003;97:234-41.

31. Price DB, Hernandez D, Magyar P, et al. Randomised controlled trial of montelukast plus inhaled budesonide versus double dose inhaled budesonide in adult patients with asthma. Thorax 2003;58:211-16

32. Fish JE, Israel E, Murray JJ, et al. Salmeterol powder provides significantly better benefit than montelukast in asthmatic patients receiving concomitant inhaled corticosteroid therapy. Chest 2001;120:423-30.

33. Tattersfield AE, Knox AJ, Britton JR, et al. Asthma. Lancet 2002;360:1313-22.

34. Boushey HA, Sorkness CA, King TS, et al. Daily versus as-needed corticosteroids for mild persistent asthma. N Engl J Med 2005;352:1519-28.

35. Suissa S, Ernst P, Benayoun S, et al. Low-dose inhaled corticosteroids and the prevention of death from asthma. N Engl J Med 2000;343:332-6.

36. Adams NP, Bestall JB, Malouf $R$, et al. Inhaled beclomethasone versus placebo for chronic asthma. Cochrane Database Syst Rev. Chichester: Wiley InterScience, 2005:CD002738.

37. Nelson HS, Weiss ST, Bleecker ER, et al. The Salmeterol Multicenter Asthma Research Trial: a comparison of usual pharmacotherapy for asthma or usual pharmacotherapy plus salmeterol. Chest 2006;129:15-26.

38. Salpeter SR, Buckley NS, Ormiston TM, et al. Meta-analysis: effect of long-acting $\{$ beta\}-agonists on severe asthma exacerbations and asthma-related deaths. Ann Intern Med 2006;144:904-12

39. Johnson M. The beta-adrenoceptor. Am J Respir Crit Care Med 1998;158:S146-53.

40. Williamson PR, Gamble C, Altman DG, et al. Outcome selection bias in metaanalysis. Stat Methods Med Res 2005;14:515-24.

41. Heaney LG, Robinson DS. Severe asthma treatment: need for characterising patients. Lancet 2005;365:974-6.

42. MSD SHARP\&DOHME GMBH. A randomised, double-blind, multicenter study to evaluate the effect of adding either montelukast sodium or salmeterol xinafoate to inhaled fluticasone in adult asthmatics (IMPACT Study-Investigation of Montelukast as a Partner Agent for Complementary Therapy)—Study 908-0C. 2002; MSD CDSP Singulair 908-0C Statistical Report.
43. MSD SHARP\&DOHME GMBH. A randomized, double-blind multicenter study to evaluate the effects of adding either montalukast sodium or salmeterol xinafoate to inhaled fluticasone in adult asthmatics-Study MK-0476 120-01 (SNG 477). 2001; MSD Results Synopsis.

44. Glaxo Wellcome. A multicenter, randomized, double-blind parallel group, 12 week active control comparison of salmeterol/fluticasone propionate combination product $(50 / 100 \mathrm{mcg} B I D)$ via the DISKUS inhaler with fluticasone propionate (100 mcg BID) via the DISKUS plus oral montelukast $(10 \mathrm{mg} \mathrm{OD})$ in adults and adolescents with persistent asthma experiencing symptoms on inhaled corticosteroid therapy-Study SAS40018. 2000; Glaxo Wellcome Report No RM2000/00232/00.

45. GlaxoSmithKline. A multi-center, randomized, double-blind, double dummy, parallelgroup, 12 week active control comparison of salmeterol/fluticasone propionate combination product $(50 / 100 \mathrm{mcg} B I D)$ via the DISKUS inhaler with fluticasone propionate (100 mcg BID) via the DISKUS plus oral montelukast $(10 \mathrm{mg} \mathrm{OD})$ in adults and adolescents with persistent asthma experiencing symptoms on inhaled corticosteroid therapy—study SAS40018. http://ctr.gsk.co.uk/Summary/ fluticasone salmeterol/studylist.asp (accessed 4 November 2007).

46. GlaxoSmithKline. A multicentre, randomised, double-blind, double-dummy, parallel group, 12-week, active control comparison of the salmeterol/fluticasone propionate combination product (50/100 mcg strength) bd via the DISKUS/ACCUHALER inhaler with fluticasone propionate (100 mcg strength) bd via the DISKUS/ACCUHALER inhaler plus oral montelukast $10 \mathrm{mg}$ od in adolescents and adults with reversible airways obstruction—study SAS40015. 2003; GlaxoSmithKline Report No BP2001/ 00015/00.

47. GlaxoSmithKline. A multicentre, randomised, double-blind, double-dummy, parallelgroup, 12-week, active control comparison of the salmeterol/fluticasone propionate combination product (50/100 mcg strength) bd via the DISKUS/ACCUHALER inhaler with fluticasone propionate (100 mcg strength) bd via the DISKUS/ACCUHALER inhaler plus oral montelukast $10 \mathrm{mg}$ od in adolescents and adults with reversible airways obstruction—Study SAS40015. http://ctr.gsk.co.uk/Summary/ fluticasone salmeterol/studylist.asp (accessed 4 November 2007).

48. GlaxoSmithKline. A phase IV, multicentre, randomised, double blind, single dummy, parallel group study to compare the anti-inflammatory action of Seretide 50/100 bd via MDI with Flixotide 100 ug bd via MDI plus Montelukast $10 \mathrm{mg}$ od for 12 weeks in adults with mild to moderate asthma who are currently taking inhaled corticosteroids but have a requirement for further therapy — study SAM40030. http://ctr.gsk.co.uk/ Summary/fluticasone salmeterol/studylist.asp (accessed 4 November 2007).

49. Holt S, Suder A, Weatherall M, et al. Dose-response relation of inhaled fluticasone propionate in adolescents and adults with asthma: meta-analysis. $B M J$ 2001;323:253-6.

50. Masoli M, Holt S, Weatherall M, et al. Dose-response relationship of inhaled budesonide in adult asthma: a meta-analysis. Eur Respir J 2004;23:552-8. 